\title{
Mitogen-activated Protein Kinase Phosphatase-1 in Rat Arterial Smooth Muscle Cell Proliferation
}

\author{
Kaihua Lai, ${ }^{*}$ Hong Wang, ${ }^{\star}$ Wen-Sen Lee, ${ }^{\star \ddagger}$ Mukesh K. Jain, ${ }^{*}$ Mu-En Lee, ${ }^{\star \ddagger \S}$ and Edgar Haber ${ }^{\star \ddagger}$ \\ *Cardiovascular Biology Laboratory, Harvard School of Public Health, Boston, Massachusetts 02115; ${ }^{\ddagger}$ Department of Medicine, \\ Harvard Medical School, Boston, Massachusetts 02115; and ${ }^{\S}$ Cardiovascular Division, Brigham and Women's Hospital, \\ Boston, Massachusetts 02115
}

\begin{abstract}
Smooth muscle cell proliferation and migration is important in arteriosclerosis. In this process, cytokines and growth factors are upregulated and bind to their respective receptors, which in turn stimulate mitogen-activated protein (MAP) kinases. MAP kinases then relay signals to the nucleus that activate quiescent smooth muscle cells. Phosphatases downregulate MAP kinases. We investigated the role of a dual-specificity tyrosine phosphatase, MAP kinase phosphatase-1 (MKP-1), in smooth muscle cell proliferation. MKP-1 expression was high in arterial tissue by Northern analysis, and MKP-1 message was detected mainly in the arterial smooth muscle layer by in situ hybridization. After balloon injury of the rat carotid artery, expression of MKP-1 decreased greatly, whereas that of MAP kinases, especially p44 MAP kinase, increased. The time course of the reduction in MKP-1 message correlated with increased tyrosine phosphorylation and elevated p44 MAP kinase enzymatic activity. In rat arterial smooth muscle cells overexpressing MKP-1, growth was arrested in the G1 phase and entry into the $S$ phase was blocked. A reduction in MKP-1 expression may contribute in part to proliferation of smooth muscle cells after vascular injury, possibly through a decrease in dephosphorylation of p44 MAP kinase. ( J. Clin. Invest. 1996. 98:1560-1567.) Key words: carotid artery • cell cycle • gene expression regulation • growth
\end{abstract}

\section{Introduction}

Proliferation and migration of smooth muscle cell(s) (SMC) ${ }^{1}$ is a hallmark of the arteriosclerotic lesion (1). SMC migrate from the media to the intima bordering the lumen and proliferate in situ $(1,2)$. Such growth leads to a gradual narrowing of the arterial lumen, which in time results in thrombosis and conse-

Address correspondence to Edgar Haber, Cardiovascular Biology Laboratory, Harvard School of Public Health, 677 Huntington Avenue, Boston, MA 02115. Phone: 617-432-1010; FAX: 617-432-4098; E-mail: haber@cvlab.harvard.edu

Received for publication 27 March 1996 and accepted in revised form 24 July 1996

1. Abbreviations used in this paper: MAP kinase, mitogen-activated protein kinase; MKP-1, MAP kinase phosphatase-1; SMC, smooth muscle cell(s).

J. Clin. Invest.

(C) The American Society for Clinical Investigation, Inc. 0021-9738/96/10/1560/08 \$2.00

Volume 98, Number 7, October 1996, 1560-1567 quent ischemia or infarction of the tissue perfused by the vessel $(1,3)$. Elucidation of the molecular mechanisms regulating SMC proliferation may provide insights into the prevention and treatment of arteriosclerosis.

Mitogen-activated protein (MAP) kinase phosphatase-1 (MKP-1) is a member of the rapidly growing dual-specificity tyrosine phosphatase family, which dephosphorylate both the phosphotyrosine and the phosphoserine/phosphothreonine residues on target proteins (4-7). Other members of this family include CDC25, Cdi1 (KAP), HVH2, VHR, PAC1, MKP-2, and B23 (8-16). These phosphatases show little similarity in sequence to the prototype tyrosine phosphatase PTP1B, except for a conserved catalytic motif (17). The substrates of this family are restricted to proteins with adjacent phosphorylated tyrosine and threonine residues. Proteins known to be phosphorylated in this manner include CDC2, CDK4, and the MAP kinases $(9,10,18,19)$, all of which are critical in the regulation of cell growth.

MKP-1 (mouse homologue, 3CH134, or Erp; human homologue, CL100) was originally cloned as an immediate early gene in fibroblasts subjected to oxidative stress. Keyse and Emslie (12) isolated CL100 from hydrogen peroxide-stimulated human skin fibroblasts, and Charles et al. (13) cloned mitogen-stimulated phosphatase $3 \mathrm{CH} 134$ from mouse fibroblasts. Others isolated the same gene after serum stimulation of quiescent fibroblasts $(11,20)$. CL100 and 3CH134 were later shown to be nearly identical (11), and both dephosphorylate phosphotyrosine, phosphothreonine, or phosphoserine on artificial substrates $(4,21)$. The gene products are now commonly referred to as MKP-1 because of their specificity for MAP kinases.

Using the coimmunoprecipitation technique, Sun et al. (5) demonstrated that MKP-1 was associated with MAP kinases p42 and p44. Transient transfection of MKP-1 into COS cells inactivated MAP kinases induced by mitogens. Similar experiments also showed MAP kinase to be the best substrate for MKP-1 in vitro (4). Although these studies have advanced our understanding of the role of MKP-1 in maintaining a balance between MAP kinase phosphorylation and dephosphorylation, the precise function of MKP-1 in the regulation of MAP kinase phosphorylation in vivo, especially in specific cell types or tissues, remains poorly understood.

MKP-1 is expressed in cultured arterial SMC and regulated by multiple signaling molecules that include growth factors, hydrogen peroxide, phorbol ester, and angiotensin II $(22,23)$. Introduction of an antisense oligonucleotide to MKP-1 has been shown to increase MAP kinase activity in transfected cells (24), but the effect on SMC proliferation of this decrease in MKP-1 activity has not been described. In addition, no direct evidence of a role for MKP-1 in cell cycle regulation has been available, even though a role for MKP-1 in the G1-S transition in fibroblasts has been suggested (25). Here we present 
evidence of a temporal association between downregulation of MKP-1 and SMC proliferation in the balloon-injured rat carotid artery. We also show that overexpression of MKP-1 restrained the growth of arterial SMC in vitro by blocking the G1-S transition.

\section{Methods}

Cell culture. Rat pulmonary artery SMC were maintained in DME (Fisher Scientific Co., Pittsburgh, PA), $25 \mathrm{mM}$ Hepes, $2 \mathrm{mM}$ glutamate, $100 \mathrm{U} / \mathrm{ml}$ penicillin, and $100 \mu \mathrm{g} / \mathrm{ml}$ streptomycin, referred to hereafter as culture medium, supplemented with $10 \%$ FCS (Hyclone, Logan, UT). Transfected cells were maintained in culture me-

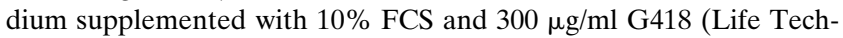
nologies, Inc., Grand Island, NY).

Rat pulmonary artery SMC were transfected stably with MKP-1 by using the Lipofectin reagent (Life Technologies, Inc.) according to the manufacturer's instructions. After transfection, cells were cultured overnight, divided one to five, and placed in culture medium supplemented with $10 \%$ FCS and $500 \mu \mathrm{g} / \mathrm{ml} \mathrm{G} 418$ for selection of those carrying a neomycin-resistant plasmid. After 4-8 wk of selection, individual cell colonies were transferred to 6-well plates for clone expansion and were maintained in culture medium supplemented with $10 \%$ FCS and $300 \mu \mathrm{g} / \mathrm{ml} \mathrm{G} 418$. MKP-1-transfected rat pulmonary artery SMC clones were identified by Northern blotting and immunochemical staining first with an antibody to an MKP-1 COOH-terminal peptide (25), and second with a rhodamine-labeled antibody to rabbit Ig (Kirkegaard \& Perry Laboratories, Gaithersburg, MD).

$R N A$ isolation and protein homogenate preparation. Male rats subjected to balloon injury of the left carotid artery (or not) were purchased from Zivic Miller Laboratories (Zelienople, PA). At various points after balloon injury, rats were anesthetized intraperitoneally by injection of $4 \%$ chloral hydrate. Injured left carotid and uninjured right carotid (control) arteries were isolated (an effort was made to remove as much surrounding connective tissue as possible during dissection), washed in cold PBS $\left(4^{\circ} \mathrm{C}\right)$, and frozen immediately in liquid nitrogen. Aorta, heart, lung, liver, kidney, and spleen were also isolated, rinsed in PBS, and immersed in liquid nitrogen. Samples were stored at $-80^{\circ} \mathrm{C}$ until use. Tissue in $15-\mathrm{ml} \mathrm{Falcon}$ tubes was homogenated on ice in a Polytron apparatus (Kinematica, Lucerne, Switzerland), with RIPA buffer (50 mM Tris-Cl, pH 7.4, $150 \mathrm{mM} \mathrm{NaCl}, 1 \%$ NP-40, $0.25 \%$ sodium deoxycholate, $1 \mathrm{mM}$ phenylmethyl sulfonyl fluoride, $1 \mathrm{mM} \mathrm{NaF}, 1 \mathrm{mM} \mathrm{Na}_{3} \mathrm{VO}_{4}, 1 \mu \mathrm{g} / \mathrm{ml}$ aprotinin, and $1 \mu \mathrm{g} / \mathrm{ml} \mathrm{leu-}$ peptin) or RNazol B plus (Tel-Test, Friendswood, TX) for RNA isolation. Total RNA was isolated according to the manufacturer's instructions. Protein homogenate was centrifuged at 12,000 $\mathrm{g}$ for 10 min to remove tissue debris. The supernatant was used to determine MAP kinase activity and to measure MAP kinase phosphorylation by Western blotting. RNA was extracted from cultured cells with RNazol B plus. Cells were lysed in RIPA buffer and disrupted by passage through a G22 needle five times. Cell debris was removed by centrifugation at $14,000 \mathrm{~g}$ for $12 \mathrm{~min}$. The supernatant was used as cell lysate for Western blotting. The Protein Assay Kit (Bio-Rad Laboratories, Hercules, CA) was used to measure protein concentrations against a BSA standard.

Immunoprecipitation and Western blotting. Carotid artery homogenates were cleared through protein G-plus agarose beads (Pharmacia LKB Biotechnology Inc., Piscataway, NJ) for $30 \mathrm{~min}$ at $4^{\circ} \mathrm{C}$. Tyrosine-phosphorylated protein in the cleared homogenate was precipitated overnight at $4^{\circ} \mathrm{C}$ on agarose beads coated with monoclonal antiphosphotyrosine antibody 4G10 (Upstate Biotechnology Inc., Lake Placid, NY). The beads were washed twice in RIPA buffer and once in PBS, and then resuspended in $1 \times$ SDS-PAGE buffer. After they had been boiled for $5 \mathrm{~min}$ at $100^{\circ} \mathrm{C}$, the beads were spun down and the supernatant was subjected to $12 \%$ SDS-PAGE. Western blotting was carried out as described by the manufacturer (ECL; Amersham Corp., Arlington Heights, IL). Phosphorylated MAP ki- nases were detected by chemiluminescence, with a polyclonal primary antibody to the MAP kinase $\mathrm{COOH}$-terminal (Upstate Biotechnology Inc.) and a horseradish peroxidase-conjugated secondary antibody to rabbit Ig.

Northern blotting. To generate a rat MKP-1 DNA fragment for Northern blotting by reverse-transcriptase PCR, we used total RNA from rat SMC as a template and oligonucleotides 331 (5'TATCGTGCCCAACGCTGAAC $3^{\prime}$ ) and 1015 (5'CCGCCTCTGCTTCACAAACTCAAAG $3^{\prime}$ ) as primers. The former corresponds to positions $331-$ 350 of the sense sequence of mouse MKP-1, the latter to positions 991-1015 of the antisense sequence. The 693 bp of rat MKP-1 DNA generated was then sequenced by dideoxy chain termination. It was $93 \%$ homologous to mouse MKP-1 cDNA (7). We used the TA cloning kit (Invitrogen Corp., San Diego, CA) to incorporate this rat MKP-1 fragment into pCR II with a sense strand under control of the $\mathrm{T} 7$ promoter, to produce the plasmid pCR II-RMKP1.

RNA blotting was performed as described (26). In brief, the isolated carotid artery RNA was loaded onto a $1 \%$ agarose gel containing $2 \%$ formaldehyde. RNA was transferred to a Hybond-C Extra nitrocellulose membrane (Amersham Corp., Life Sciences, Arlington Heights, IL) after electrophoresis. Rat carotid artery MKP-1 mRNA was detected by hybridization (in QuickHyb solution; Stratagene Inc., La Jolla, CA) with a randomly primed rat MKP-1 cDNA probe, whereas overexpressed human MKP-1 mRNA in rat pulmonary artery SMC was detected with a randomly primed human MKP-1 cDNA probe. The membrane was washed in $0.2 \times \mathrm{SSC} / 0.1 \% \mathrm{SDS}$ for 10 min once at room temperature and again at $56^{\circ} \mathrm{C}$ and exposed to a phosphor imaging cassette (Molecular Dynamics, Inc., Sunnyvale, CA) and X-Omat film (Eastman Kodak Co., Rochester, NY). To correct for differences in loading, we blotted the membrane with the ${ }^{32} \mathrm{P}$ labeled oligonucleotide 5'AACGATGAGTAGTGGTATTTCACC 3', which corresponds to the sequence spanning positions 4011-4036 of 28S ribosomal RNA. Rat MKP-1 and rRNA signals were measured with the ImageQUANT program (Molecular Dynamics, Inc.).

Construction of MKP-1 overexpression vector. The EcoRI and XbaI fragments of full-length human MKP-1 (12) in pcDNA1 were subcloned into pcDNA3 (Invitrogen Corp.) for stable transfection and overexpression of MKP-1 in rat pulmonary artery SMC. The orientation of the MKP-1 insert in pcDNA3 was confirmed by restriction digestion and dideoxy chain termination sequencing (26). MKP-1 was overexpressed under control of the cytomegalovirus promoter in the pcDNA3 vector.

Flow cytometry. Cells $\left(5 \times 10^{5}\right)$ were seeded on $100-\mathrm{mm}$ dishes and cultured to $\sim 40 \%$ confluence. They were then rendered quiescent by incubation for $4 \mathrm{~d}$ in culture medium supplemented with $0.4 \%$ calf serum and $300 \mu \mathrm{g} / \mathrm{ml} \mathrm{G} 418$. Cells were released from quiescence with culture medium supplemented with $2 \%$ calf serum and $300 \mu \mathrm{g} /$ $\mathrm{ml} \mathrm{G} 418$. Cells were harvested at various times after release with trypsin-EDTA, washed twice with $\mathrm{PBS} / 0.1 \%$ dextrose, and fixed in $70 \%$ ethanol at $4^{\circ} \mathrm{C}$. The fixed cells were stained with a solution containing propidium iodine $(50 \mu \mathrm{g} / \mathrm{ml})$ and DNase-free RNase $(2 \mathrm{U} / \mathrm{ml})$ and subjected to FACS ${ }^{\circledR}$ analysis of DNA content.

Determination of MAP kinase activity. The serine/threonine kinase activity of MAP kinase can be determined directly by using artificial substrates such as myelin basic protein or indirectly by studying MAP kinase tyrosine phosphorylation by Western blotting. In addition to examining tyrosine phosphorylation of MAP kinases by immunoprecipitation and Western blotting (described above), we measured MAP kinase activity with an in-gel assay in which myelin basic protein was used as substrate, as described by Chao et al. (27) with slight modification. Samples containing equal amounts of protein were subjected to $12 \%$ SDS-PAGE with $0.5 \mathrm{mg} / \mathrm{ml}$ myelin basic protein copolymerized in the gel. After electrophoresis, the gels were washed twice with $50 \mathrm{mM}$ Tris-Cl, $\mathrm{pH} 8.0$, in $20 \%$ 2-propanol and allowed to soak for $1 \mathrm{~h}$. They were then denatured in $6 \mathrm{M}$ guanidine chloride for $1 \mathrm{~h}$ and renatured in $50 \mathrm{mM}$ Tris-Cl, $\mathrm{pH} 8.0,0.04 \%$ Tween 20, and $5 \mathrm{mM} 2$-mercaptoethanol. Renatured gels were incubated with reaction buffer (40 mM Hepes, $\mathrm{pH}$ 8.0, 0.5 mM EGTA, 
$10 \mathrm{mM} \mathrm{MgCl}, 2 \mu \mathrm{M}$ protein kinase inhibitor, $40 \mu \mathrm{M} \mathrm{ATP}$, and $35 \mu \mathrm{Ci}$ $\gamma-{ }^{32} \mathrm{P}$-ATP) for $1 \mathrm{~h}$. The gels were then washed with $5 \%$ TCA and $1 \%$ tetrasodium pyrophosphate until radioactivity in the solution was negligible, dried, and autoradiographed.

In situ hybridization. ${ }^{33} \mathrm{P}-\mathrm{UTP}-$ labeled MKP-1 antisense and sense riboprobes were prepared from plasmid pCR II-RMKP1 templates that had been linearized by XbaI (antisense) and HindIII (sense) cutting. The antisense riboprobe was generated with SP6 RNA polymerase, the sense riboprobe with T7 RNA polymerase. Both riboprobes were reduced by partial $\mathrm{NaHCO}_{3}$ hydrolysis. Male Sprague-Dawley rats were perfused with $4 \%$ paraformaldehyde. The left carotid artery was removed, postfixed in $4 \%$ paraformaldehyde at $4{ }^{\circ} \mathrm{C}$ overnight, and immersed in $30 \%$ sucrose for $2 \mathrm{~d}$. Cryosections were cut to a $5-\mu \mathrm{m}$ thickness and hybridized in situ with radiolabeled probes as described (28). Dry tissue sections were dipped in NTB2 emulsion (Eastman Kodak Co.) and exposed for $1 \mathrm{wk}$ at $4^{\circ} \mathrm{C}$. Tissue sections were counterstained with hematoxylin-eosin and photographed under darkfield illumination onto Ektar-25 film (Eastman Kodak Co.).

\section{Results}

Activation of MAP kinase by vascular injury. Balloon injury of the rat carotid artery is a well established model for studying SMC proliferation and migration resulting from mechanical injury (29). Because MAP kinase activation accompanies a number of cellular functions such as proliferation and differentiation $(30,31)$, we investigated whether MAP kinase is activated in response to balloon injury. Increases in tyrosine phosphorylation of the enzyme itself or in phosphorylation of

A

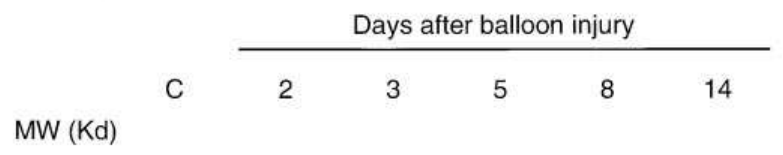

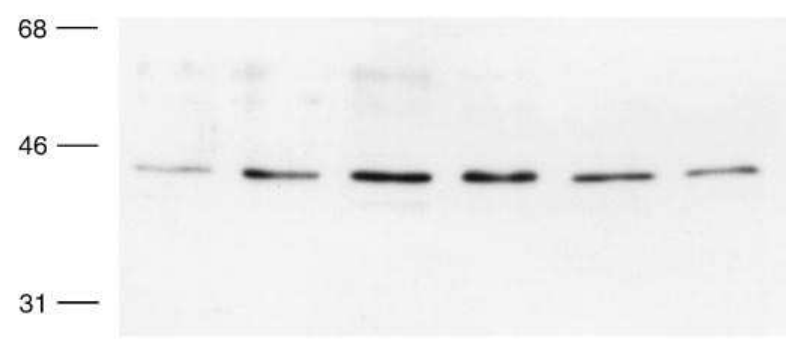

B

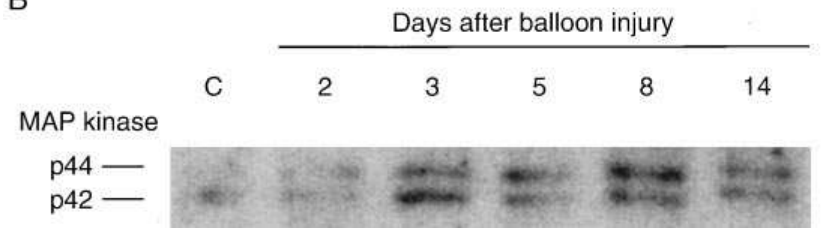

Figure 1. MAP kinase activation in rat carotid artery after balloon injury. (A) Tyrosine phosphorylation of MAP kinases. Protein $(50 \mu \mathrm{g})$ from carotid artery homogenate was used to immunoprecipitate tyrosine phosphorylated proteins. Tyrosine phosphorylated MAP kinases were detected with an anti-MAP kinase antibody. (B) Phosphorylation of myelin basic protein by MAP kinases p44 and p42. Protein $(20 \mu \mathrm{g})$ from carotid artery homogenate was used to determine MAP kinase activity. The activity of MAP kinases p44 and p42 is indicated by ${ }^{32} \mathrm{P}$ phosphorylation of myelin basic protein in the gel (see Determination of MAP kinase activity in Methods). This experiment was repeated, with similar results.
A

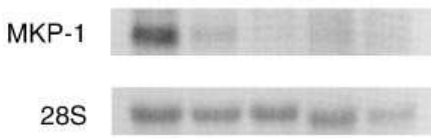

Figure 3. Time course of MKP-1 mRNA expression after balloon injury of the rat carotid artery. $(A)$ Northern analysis of MKP-1 mRNA level in comparB

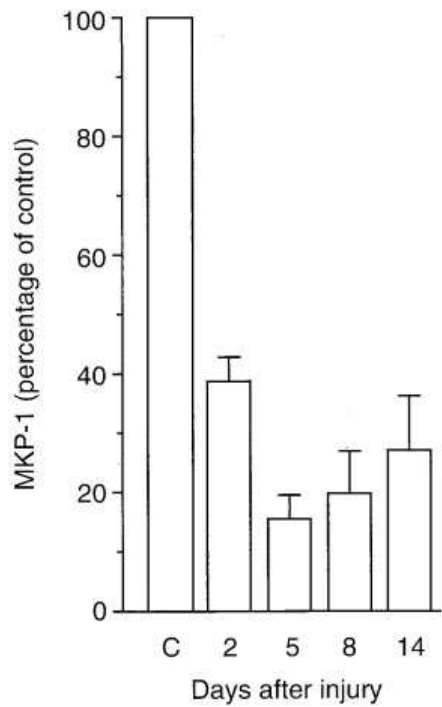

ison with that of $28 \mathrm{~S}$ rRNA. (B) Quantitative analysis of MKP-1 mRNA expression after balloon injury. MKP-1 signals were corrected against those for 28S rRNA to equalize loading; the MKP-1 signal from the pool of uninjured right carotid arteries removed from the same animals in which the left carotid artery had been injured was used as a control (set at 100\%). Values represent the mean \pm SEM from three individual experiments. Day $2,5,8$, and 14 values were significantly lower

than the control value $(P<0.01)$. The values for days 5,8 , and 14 did not differ significantly from one another $(P>0.05)$.

model substrates such as myelin basic protein indicate MAP kinase activation. Fig. $1 A$ shows that tyrosine phosphorylation of MAP kinase increased from days 2 to 8 after injury of the left carotid artery (day 2, 263\%; day 3,367\%; day 5, 316\%; day $8,268 \%)$ and decreased slightly at day 14 (167\% increase; all increases relative to uninjured right carotid artery control value of $100 \%$ ). Tyrosine phosphorylation appeared to increase markedly in MAP kinase p44 (heavy bands) but only slightly in MAP kinase p42 (light bands). To confirm this observation, we directly measured MAP kinase activity on myelin basic protein (Fig. $1 \mathrm{~B}$ ). p44 Tyrosine kinase activity began to increase $2 \mathrm{~d}$ after balloon injury, reached a peak at 5-8 d, and decreased slightly thereafter; the pattern was similar for $\mathrm{p} 42$. Phosphorylation of other MAP kinases was not observed. Thus the time course of substrate phosphorylation (Fig. $1 B$ ) closely followed that of MAP kinase tyrosine phosphorylation (Fig. $1 A$ ). In contrast, MAP kinase activity did not change significantly in the uninjured right carotid arteries at time points corresponding to those in Fig. 1 (reflected by MAP kinase phosphorylation: control, $100 \%$; day $3,150 \%$; day 5, $100 \%$; day $8,100 \%$; day $14,131 \%$ ).

Tissue distribution of MKP-1 expression. To determine whether this increase in MAP kinase activity was associated with changes in MKP-1 gene expression, we first determined whether MKP-1 was expressed in the artery. Normal rat carotid artery expressed MKP-1 mRNA abundantly in comparison with liver, kidney, and spleen (Fig. $2 A$ ). The level of MKP-1 mRNA in the carotid artery was about $50 \%$ that in the lung, which showed the highest level of MKP-1 expression among the organs examined. The aorta, another blood vessel, also expressed MKP-1 highly, at a level similar to that in the 
A

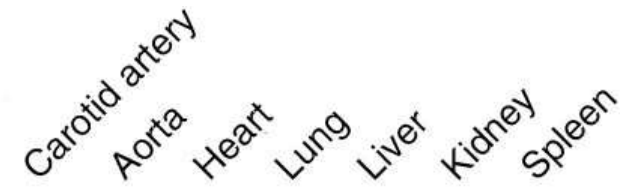

MKP-1

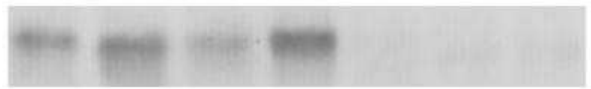

$28 \mathrm{~S}$

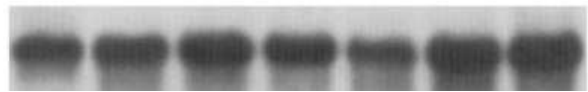

B

Antisense

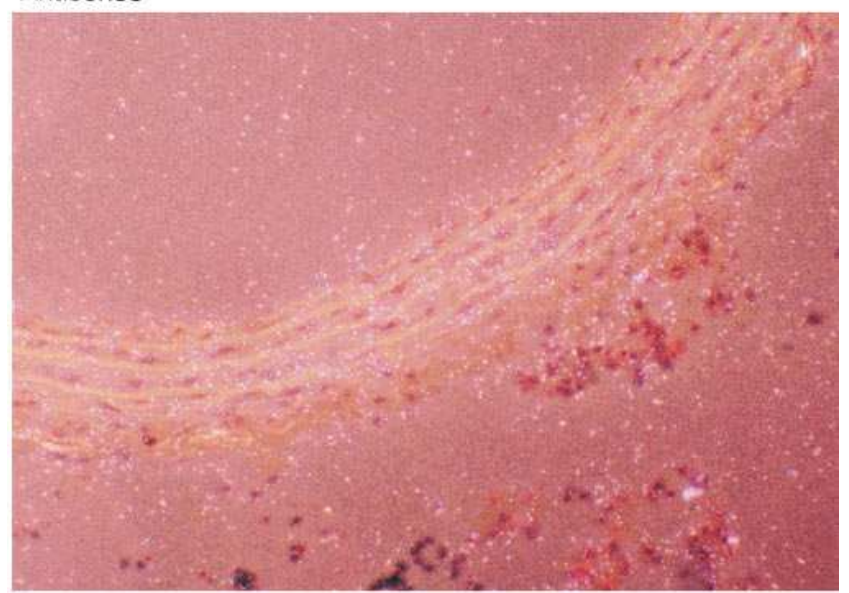

Sense

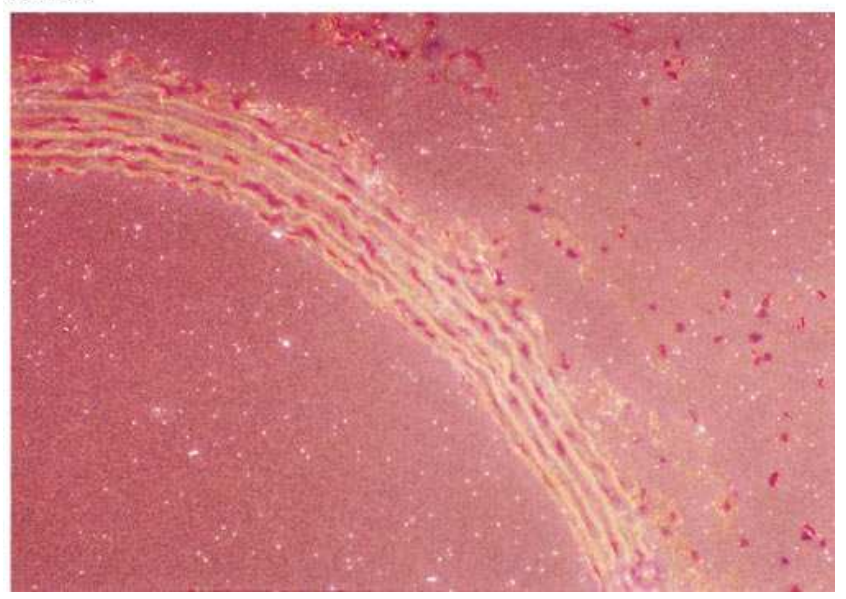

Figure 2. Tissue distribution of MKP-1 mRNA expression. ( $A$ )

Northern analysis of MKP-1 mRNA level in comparison with that of $28 \mathrm{~S}$ rRNA. (B) In situ hybridization of normal rat carotid artery with antisense (top) and sense (bottom) MKP-1 riboprobe.

carotid artery. MKP-1 expression in the heart was lower than in the carotid artery and aorta, but higher than in the liver, kidney, and spleen. During dissection of the carotid artery, we largely removed the outer connective tissue layer and the adventitia. Therefore it is likely that the expressed MKP-1

Ig. The signal was visualized in a fluorescence microscope and photographed on ASO 400 film (Eastman Kodak Co.).
A

\section{Transfected clone}

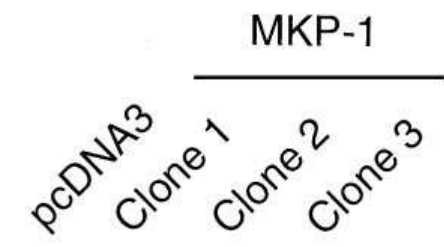

MKP-1

$28 \mathrm{~S}$

B

\section{pcDNA3}

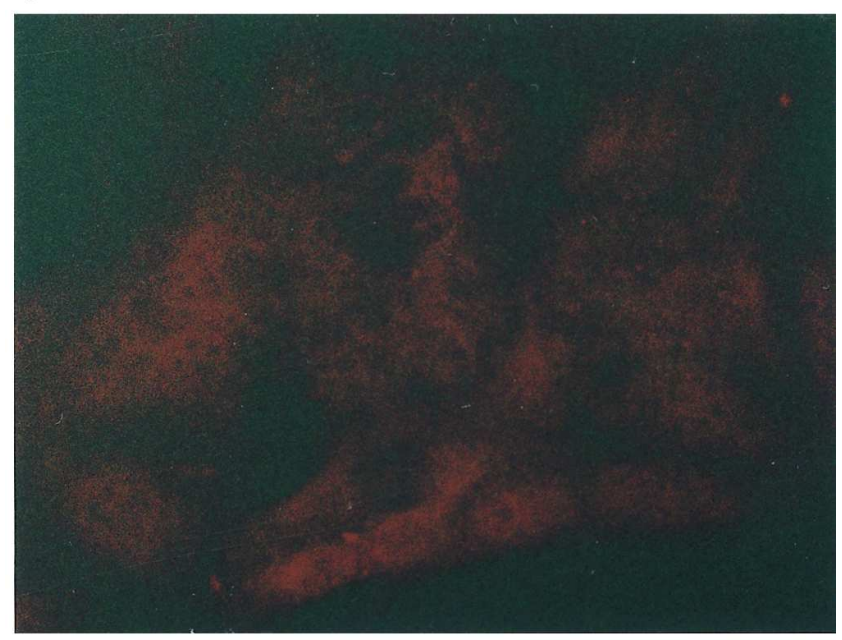

MKP-1

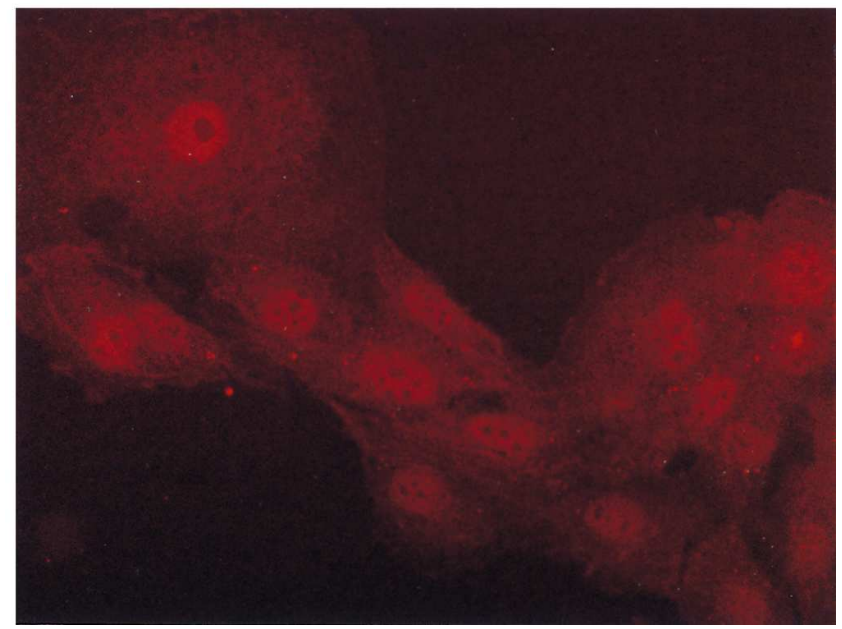

Figure 4. Overexpression of MKP-1 in rat pulmonary artery SMC. (A) Northern blotting of MKP-1 signal. Clones expressing MKP-1 were cultured in medium supplemented with $2 \%$ calf serum and 300 $\mu \mathrm{g} / \mathrm{ml} \mathrm{G} 418$. RNA was isolated and blotted with a randomly primed human MKP-1 probe. $(B)$ Indirect immunostaining of MKP-1 in rat pulmonary artery SMC transfected with control vector ( $p c D N A 3)$ alone or vector MKP-1 (MKP-1). Cells were cultured on glass slides as in $A$, fixed in $4 \%$ paraformaldehyde, and immunoblotted with an antibody to MKP-1 and an antibody to rhodamine-conjugated rabbit 


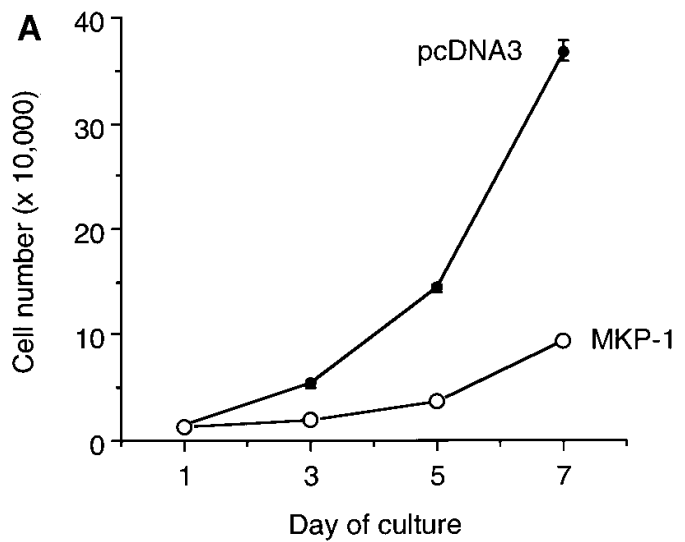

B

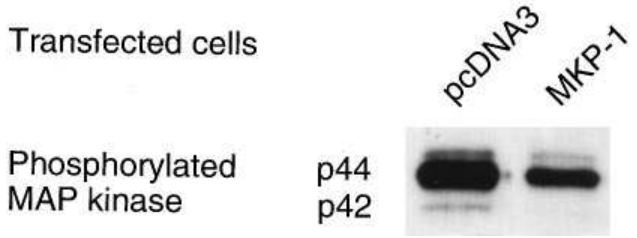

Figure 5. (A) Growth of rat pulmonary artery SMC transfected with MKP-1. Cells transfected with MKP-1 and pcDNA3 were seeded at 20,000/well on 6-well plates and cultured in medium supplemented with $2 \%$ calf serum and $300 \mu \mathrm{g} / \mathrm{ml} \mathrm{G} 418$. Cells were harvested and counted at the indicated times in a Coulter apparatus. Values represent the mean \pm SEM from three individual experiments. (B) MAP kinase activity in MKP-1-transfected cells. Cells were grown in DMEM with $10 \% \mathrm{FCS} / 300 \mu \mathrm{g} / \mathrm{ml} \mathrm{G} 418$. Lysates were prepared as described in Methods. Activated MAP kinases that had been tyrosine phosphorylated were immunoprecipitated on agarose beads conjugated to an antiphosphotyrosine antibody and then subjected to Western blotting with an anti-MAP kinase antibody.

mRNA originated from the SMC layer (the media) or the endothelium. We confirmed expression of MKP-1 in SMC from normal (uninjured) carotid arteries by in situ hybridization (Fig. $2 \mathrm{~B}$ ). Most of the MKP-1 message was detected in the media (38 \pm 7 grains $/ \mathrm{cm}^{2}, 200$ power field); the adventitia contained less MKP-1 message (13 \pm 5 grains $\left./ \mathrm{cm}^{2}, P<0.01\right)$.

Reduction in MKP-1 $\mathrm{mRNA}$ after balloon injury. MKP-1 mRNA was examined in the left carotid artery before and 2, 5, 8 , and $14 \mathrm{~d}$ after balloon injury. The MKP-1 mRNA level did not change within $1 \mathrm{~d}$ of injury (data not shown). However, within $2 \mathrm{~d}$ of injury, MKP-1 expression decreased strikingly (Fig. 3, $A$ and $B$ ). In comparison with the level in uninjured right carotid arteries (control), MKP-1 mRNA expression was reduced to $37 \pm 4 \%$ at day 2 after injury, $15 \pm 4 \%$ at day 5 , $19 \pm 7 \%$ at day 8 , and $26 \pm 9 \%$ at day 14 . MKP-1 mRNA expression reached its minimum $5 \mathrm{~d}$ after injury and increased slightly at $14 \mathrm{~d}$. There was no significant change in MKP-1 mRNA levels in the corresponding uninjured right carotid arteries (control, $100 \%$; day 2, $108 \%$; day 5, $100 \%$; day $8,125 \%$; day $14,88 \%$ ). These observations suggest that downregulation of MKP-1 plays a role in the proliferation of arterial SMC in vivo.

Stable transfection of MKP-1 into rat pulmonary artery $S M C$. We introduced MKP-1 into rat pulmonary artery SMC to study the effect of MKP-1 overexpression on cell proliferation. Transfected clones stably expressing MKP-1 were ini- tially identified by Northern blotting with a randomly primed human MKP-1 probe. Although our probe could not completely differentiate endogenous rat MKP-1 from overexpressed human MKP-1, culturing the cells under low growth conditions ( $2 \%$ calf serum) minimized endogenous rat MKP-1 to an undetectable level (data not shown). Cells transfected with the MKP-1-expressing plasmids showed a fourfold increase in MKP-1 mRNA expression in comparison with those transfected with the pcDNA3 control plasmid (Fig. $4 A$ ). We confirmed the presence of MKP-1 protein by immunostaining with an antibody specific for its $\mathrm{COOH}$-terminal (Fig. $4 \mathrm{~B}$ ). In MKP-1-transfected cells, staining was observed primarily in the nuclei. In contrast, only $10-20 \%$ of the nuclei were stained in the pcDNA3-transfected (control) cells. These transfected cell lines were then used to study growth and passage through the cell cycle.

Growth of transfected rat pulmonary artery SMC. Growth decreased in rat pulmonary artery SMC transfected with MKP-1 in comparison with cells transfected with pcDNA3. Cell number diverged within $3 \mathrm{~d}$ of culture (Fig. $5 A$ ), and growth in MKP-1-transfected rat pulmonary artery SMC decreased to $25 \%$ of the level in pcDNA3-transfected cells over 7 $\mathrm{d}$ of culture. In comparison with cells transfected with vector, MKP-1-transfected cells showed a 40-60\% reduction in MAP kinase activity when stimulated with serum (Fig. $5 B$ ).

Retardation of the cell cycle by MKP-1. Fluorescence-activated cell sorting performed after propidium iodide staining showed that progression to the $\mathrm{S}$ phase of the cell cycle was retarded in MKP-1-transfected rat pulmonary artery SMC (Fig. 6, $A$ and $B$ ). In comparison with pcDNA3-transfected cells, which entered the $\mathrm{S}$ phase $16 \mathrm{~h}$ after release from growth inhibition, only a few MKP-1-transfected cells (12\%) began to enter the $S$ phase $22 \mathrm{~h}$ after release (a $6 \mathrm{~h}$ delay). In addition, the number of MKP-1-transfected cells at the peak of the $S$ phase $(17 \%)$ was considerably lower than the number of pcDNA3transfected cells $(45 \%)$ (Fig. $6 \mathrm{~B})$. Even after the period of release from growth inhibition had been extended to $33 \mathrm{~h}$, there was no increase in the number of MKP-1-transfected rat pulmonary artery SMC in the S through G2/M phases (G0/G1, $87 \%$; S, $8 \%$; G2/M, 5\%).

\section{Discussion}

To establish a role for MKP-1 in the control of SMC proliferation, we had to establish that the phosphatase was expressed significantly in the vessel wall. MKP-1 expression has been reported in lung and placenta (13) and in cultured SMC $(23,24)$. We found by Northern analysis of tissue from carotid artery and aorta that MKP-1 mRNA was expressed highly in both large and medium sized arteries in vivo (Fig. $2 A$ ). By in situ hybridization, we localized MKP-1 expression in the normal carotid artery mainly to the SMC layer (tunica media) and to a lesser degree to the adventitia (Fig. 2 B).

The tissue distribution of individual dual-specificity tyrosine phosphatases varies with each enzyme and reflects functions specific to tissues or cell types. For example, PAC-1, an MKP-1 homologue, is found primarily in cells of a lymphocyte lineage (32). Another homologue, MKP-2, is expressed highly in lung, brain, heart, and testis (8), and Cdi1, a dual-specificity phosphatase associated with CDK2, is expressed highly in HeLa cells, but not SMC (K. Lai, unpublished data). The high 
level of MKP-1 in arterial SMC would implicate this phosphatase in the regulation of SMC growth. The adventitia has been suggested to play an important role in the remodeling process after vascular injury (33). We show here that the level of MKP-1 message in the adventitia was about one third that in the media after vascular injury. The importance of MKP-1 expression in the adventitia has not yet been determined.

MKP-1 is a stress-stimulated, immediate early gene. This characteristic suggests an important role for MKP-1 in the cell's response to hypoxia, heat shock, oxidation, and ultraviolet radiation $(12,34-36)$. The cellular response to mechanical injury of an artery (in the rat model we studied or in therapeutic angioplasty in humans) initially involves medial SMC proliferation. SMC then migrate to the intima beneath the endothelium and proliferate again. In the rat carotid artery model, SMC proliferation in the subintima begins $48 \mathrm{~h}$ after injury, peaks after $96 \mathrm{~h}$, and gradually subsides $(29,37)$. We show here that arterial SMC proliferation was associated with upregula-
A

pcDNA3
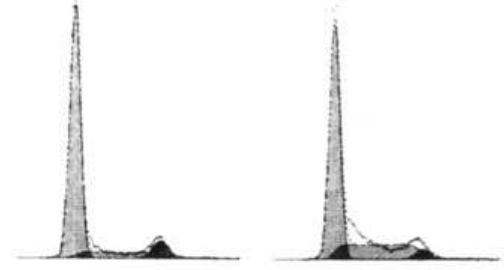

MKP-1
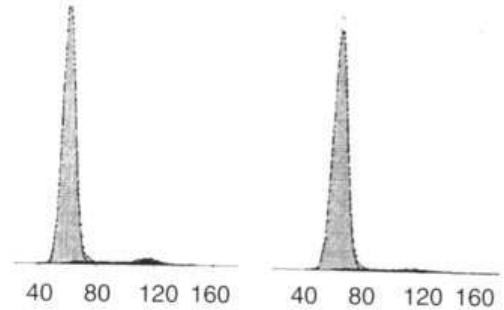

Hours

0

16

B

pcDNA3-transfected

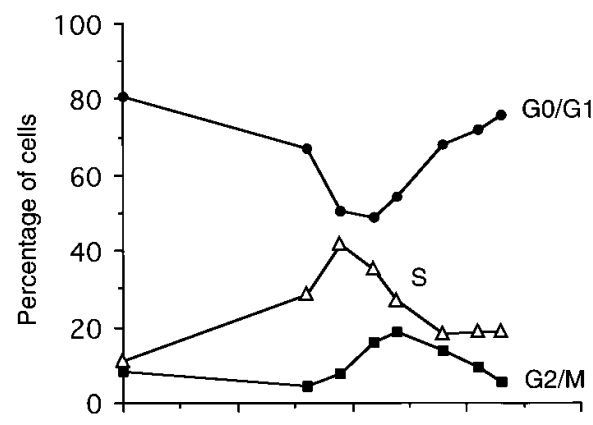

MKP-1-transfected

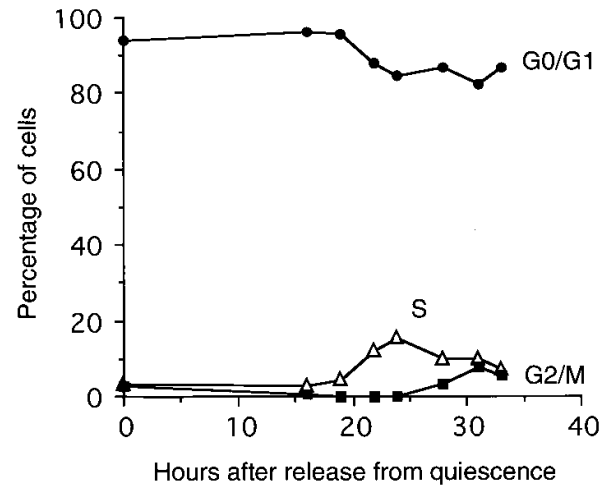

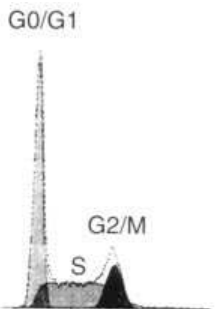
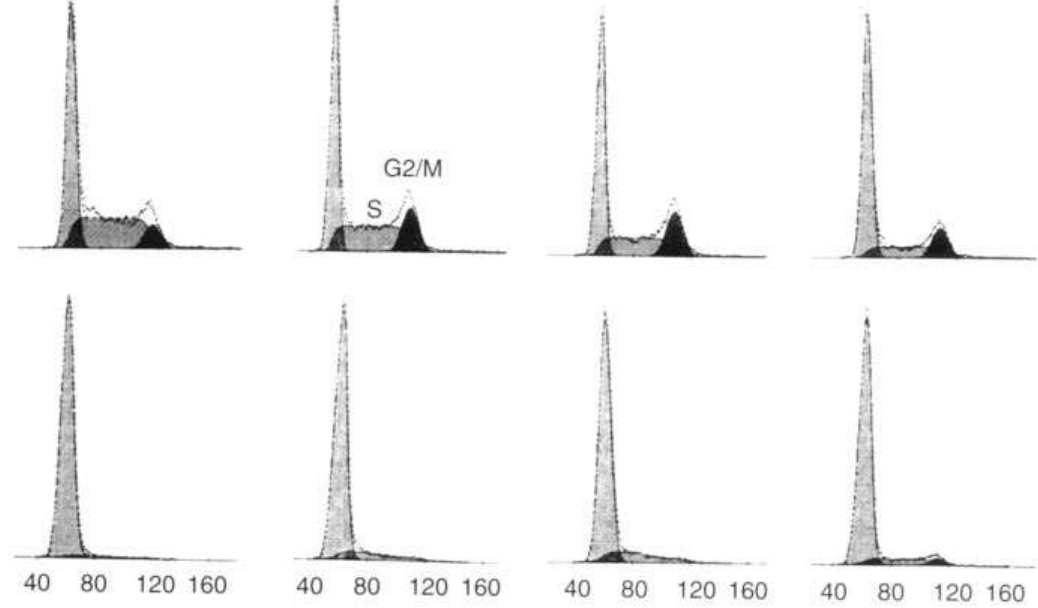

19
Figure 6. Cell cycle in rat pulmonary artery SMC transfected with control vector $(p c D N A 3)$ or vector MKP-1 (MKP-1). (A) FACS ${ }^{\circledR}$ analysis of DNA content after release from quiescence by incubation in culture medium supplemented with $2 \%$ calf serum and $300 \mu \mathrm{g} / \mathrm{ml} \mathrm{G} 418$. Tall peak on the left marks the G0/G1 phase, the plateau in the middle marks the $\mathrm{S}$ phase, and the short (dark) peak on the right marks the G2/M phase. (B) Percentage of cells in G0/G1, S, and G2/M phases of the cell cycle. 
tion of MAP kinase phosphorylation and enzymatic activity over time (Fig. 1). (Because MAP kinase activity depends primarily on tyrosine/threonine phosphorylation, we did not measure MAP kinase mRNA.) This MAP kinase activation could have resulted from a decrease in the activity of tyrosine phosphatases or an increase in the activity of upstream participants in the ras-raf-MEK-MAP kinase signaling pathway, or both. Indeed, we observed a downregulation in MKP-1 mRNA expression (Fig. 1).

In cultured arterial SMC, MKP-1 expression is under the influence of $\mathrm{Ca}^{2+}$, angiotensin II, EGF, PDGF, and $\mathrm{H}_{2} \mathrm{O}_{2}$ (23). Stimulation of MKP-1 expression coincides with a reduction in MAP kinase activity (23), and introduction of an MKP-1 antisense oligonucleotide increases MAP kinase activity in arterial SMC in a dose-dependent manner (24). MAP kinase activation results in activation of downstream transcriptional factors such as Jun, Fos, and Ets that are required for the cell to exit the G0/G1 phase (30). In addition, proliferation in many cell types is associated with transient activation of MAP kinase by mitogens (38). We have also observed that proliferation of rat pulmonary artery SMC is associated with a transient activation of MAP kinases p44 and p42 after stimulation with PDGF (data not shown). In this report, we demonstrate that transfection of MKP-1 into arterial SMC diminished cell growth, which is associated with a reduction in MAP kinase activity (Fig. 5). MKP-1 overexpression delayed the onset of the $\mathrm{S}$ phase and reduced the number of cells entering the $\mathrm{S}$ phase (Fig. 6, $A$ and $B$ ). These observations support the suggestion that MKP-1 plays a role in regulating the G0/G1 phase of the cell cycle in fibroblasts $(7,25,39)$.

Of the many tyrosine phosphatases (MKP-1, MKP-2, $\mathrm{HVH} 2$, and B23) that dephosphorylate and inactivate MAP kinases, MKP-1 has been studied the most extensively. MKP-1 inactivates $\mathrm{p} 42$ MAP kinase by dephosphorylating Thr183 and Tyr185, both in vitro and in vivo (5), and an active site mutant of MKP-1 without enzymatic activity, C258S MKP-1, binds p42 MAP kinase (5). If the MAP kinases are indeed the substrates of MKP-1, its role is probably to reverse MAP kinase activation by serum or oncogenic ras and raf $(5,39)$. It is reasonable to hypothesize that such activation may be due to an increase in MAP kinase activity and a downregulation of MKP-1. Our results suggest that MKP-1 may be important in maintaining SMC in a quiescent, nonproliferative state, which would thereby maintain the structural integrity of the artery. In a therapeutic context, the induction of MKP-1 expression could be of value in preventing unwanted SMC proliferation after angioplasty.

\section{Acknowledgments}

We thank Wilson Endege, Choon-Joo Kho, Cam Patterson, Mark Perrella, Chengwei Shi, and Masao Yoshizumi for their advice, Saori Kashiki and Donald Fletcher for performing the in situ hybridization experiments, and Thomas McVarish for editorial assistance.

This work was supported by a grant from Bristol Myers-Squibb Co. (Princeton, NJ).

\section{References}

1. Ross, R. 1993. The pathogenesis of atherosclerosis: a perspective for the 1990s. Nature (Lond.). 362:801-809.

2. Johnson, D.E., S.Z. Gao, J.S. Schroeder, W.M. DeCampli, and M.E. Billingham. 1989. The spectrum of coronary artery pathologic findings in human cardiac allografts. J. Heart Transplant. 8:349-359.

3. Campbell, J.H., and G.R. Campbell. 1994. Cell biology of atherosclerosis. J. Hypertens. 12(Suppl.):129-132.

4. Alessi, D.R., C. Smythe, and S.M. Keyse. 1993. The human CL100 gene encodes a Tyr/Thr-protein phosphatase which potently and specifically inactivates MAP kinase and suppresses its activation by oncogenic ras in Xenopus oocyte extracts. Oncogene. 8:2015-2020.

5. Sun, H., C.H. Charles, L.F. Lau, and N.K. Tonks. 1993. MKP-1 (3CH134), an immediate early gene product, is a dual specificity phosphatase that dephosphorylates MAP kinase in vivo. Cell. 75:487-493.

6. Emslie, E.A., T.A. Jones, D. Sheer, and S.M. Keyse. 1994. The CL100 gene, which encodes a dual specificity (Tyr/Thr) MAP kinase phosphatase, is highly conserved and maps to human chromosome 5q34. Hum. Genet. 93:513516 .

7. Kwak, S.P., D.J. Hakes, K.J. Martell, and J.E. Dixon. 1994. Isolation and characterization of a human dual specificity protein-tyrosine phosphatase gene. J. Biol. Chem. 269:3596-3604.

8. Misra-Press, A., C.S. Rim, H. Yao, M.S. Roberson, and P.J.S. Stork. 1995. A novel mitogen-activated protein kinase phosphatase. Structure, expression, and regulation. J. Biol. Chem. 270:14587-14596.

9. Gyuris, J., E. Golemis, H. Chertkov, and R. Brent. 1993. Cdi1, a human G1 and S phase protein phosphatase that associates with Cdk2. Cell. 75:791803.

10. Hannon, G.J., D. Casso, and D. Beach. 1994. KAP: a dual specificity phosphatase that interacts with cyclin-dependent kinases. Proc. Natl. Acad. Sci. USA. 91:1731-1735.

11. Ishibashi, T., D.P. Bottaro, P. Michieli, C.A. Kelley, and S.A. Aaronson. 1994. A novel dual specificity phosphatase induced by serum stimulation and heat shock. J. Biol. Chem. 269:29897-29902.

12. Keyse, S.M., and E.A. Emslie. 1992. Oxidative stress and heat shock induce a human gene encoding a protein-tyrosine phosphatase. Nature (Lond.). 359:644-647.

13. Charles, C.H., A.S. Abler, and L.F. Lau. 1992. cDNA sequence of a growth factor-inducible immediate early gene and characterization of its encoded protein. Oncogene. 7:187-190.

14. Ward, Y., S. Gupta, P. Jensen, M. Wartmann, R.J. Davis, and K. Kelly. 1994. Control of MAP kinase activation by the mitogen-induced threonine/tyrosine phosphatase PAC1. Nature (Lond.). 367:651-654.

15. Guan, K.L., and E. Butch. 1995. Isolation and characterization of a novel dual specific phosphatase, $\mathrm{HVH} 2$, which selectively dephosphorylates the mitogen-activated protein kinase. J. Biol. Chem. 270:7197-7203.

16. Denu, J.M., and J.E. Dixon. 1995. A catalytic mechanism for the dualspecific phosphatases. Proc. Natl. Acad. Sci. USA. 92:5910-5914.

17. Stone, R.L., and J.E. Dixon. 1994. Protein-tyrosine phosphatases. J. Biol. Chem. 269:31323-31326.

18. Atherton-Fessler, S., F. Liu, B. Gabrielli, M.S. Lee, C.Y. Peng, and H Piwnica-Worms. 1994. Cell cycle regulation of the p34cdc2 inhibitory kinases. Mol. Biol. Cell. 5:989-1001.

19. Sebastian, B., A. Kakizuka, and T. Hunter. 1993. Cdc25M2 activation of cyclin-dependent kinases by dephosphorylation of threonine-14 and tyrosine15. Proc. Natl. Acad. Sci. USA. 90:3521-3524.

20. Noguchi, T., R. Metz, L. Chen, M.-G. Mattéi, D. Carrasco, and R. Bravo. 1993. Structure, mapping, and expression of erp, a growth factor-inducible gene encoding a nontransmembrane protein tyrosine phosphatase, and effect of ERP on cell growth. Mol. Cell. Biol. 13:5195-5205.

21. Charles, C.H., H. Sun, L.F. Lau, and N.K. Tonks. 1993. The growth factor-inducible immediate-early gene $3 \mathrm{CH} 134$ encodes a protein-tyrosine-phosphatase. Proc. Natl. Acad. Sci. USA. 90:5292-5296.

22. Baas, A.S., and B.C. Berk. 1995. Differential activation of mitogen-activated protein kinases by $\mathrm{H}_{2} \mathrm{O}_{2}$ and $\mathrm{O}_{2}$ - in vascular smooth muscle cells. Circ. Res. 77:29-36.

23. Duff, J.L., M.B. Marrero, W.G. Paxton, C.H. Charles, L.F. Lau, K.E. Bernstein, and B.C. Berk. 1993. Angiotensin II induces 3CH134, a protein-tyrosine phosphatase, in vascular smooth muscle cells. J. Biol. Chem. 268:2603726040.

24. Duff, J.L., B.P. Monia, and B.C. Berk. 1995. Mitogen-activated protein (MAP) kinase is regulated by the MAP kinase phosphatase (MKP-1) in vascular smooth muscle cells. Effect of actinomycin D and antisense oligonucleotides. J. Biol. Chem. 270:7161-7166.

25. Brondello, J.M., F.R. McKenzie, H. Sun, N.K. Tonks, and J. Pouysségur. 1995. Constitutive MAP kinase phosphatase (MKP-1) expression blocks G1 specific gene transcription and S-phase entry in fibroblasts. Oncogene. 10:1895-1904.

26. Sambrook, J., E.F. Fritsch, and T. Maniatis. 1989. Molecular Cloning. 2nd ed. Cold Spring Harbor Laboratory, Cold Spring Harbor, NY.

27. Chao, T.S., K.L. Byron, K.M. Lee, M. Villereal, and M.R. Rosner. 1992. Activation of MAP kinases by calcium-dependent and calcium-independent pathways. Stimulation by thapsigargin and epidermal growth factor. J. Biol. Chem. 267:19876-19883.

28. Lee, W.S., Y. Kanai, R.G. Wells, and M.A. Hediger. 1994. The high affinity $\mathrm{Na}+$ /glucose cotransporter: re-evaluation of function and distribution of expression. J. Biol. Chem. 269:12032-12039. 
29. Clowes, A.W., M.A. Reidy, and M.M. Clowes. 1983. Kinetics of cellular proliferation after arterial injury. I. Smooth muscle growth in the absence of endothelium. Lab. Invest. 49:327-333.

30. L'Allemain, G. 1994. Deciphering the MAP kinase pathway. Prog Growth Factor Res. 5:291-334.

31. Derijard, B., J. Raingeaud, T. Barrett, I.H. Wu, J. Han, R.J. Ulevitch, and R.J. Davis. 1995. Independent human MAP-kinase signal transduction pathways defined by MEK and MKK isoforms. Science (Wash. DC). 267:682-685.

32. Gerondakis, S., C. Economou, and R.J. Grumont. 1994. Structure of the gene encoding the murine dual specificity tyrosine-threonine phosphatase PAC1. Genomics. 24:182-184.

33. Shi, Y., M. Pieniek, A., Fard, J. O'Brien, J.D. Mannion, and A. Zalewski. 1996. Adventitial remodeling after coronary arterial injury. Circulation. 93:340-348.

34. Liu, Y., M. Gorospe, C. Yang, and N.J. Holbrook. 1995. Role of mitogen-activated protein kinase phosphatase during the cellular response to genotoxic stress. Inhibition of c-Jun N-terminal kinase activity and AP-1-dependent gene activation. J. Biol. Chem. 270:8377-8380.

35. Wiessner, C., T. Neumann-Haefelin, P. Vogel, T. Back, and K.A. Hossmann. 1995. Transient forebrain ischemia induces an immediate-early gene encoding the mitogen-activated protein kinase phosphatase $3 \mathrm{CH} 134$ in the adult rat brain. Neuroscience. 64:959-966.

36. Takano, S., H. Fukuyama, M. Fukumoto, K. Hirashimizu, T. Higuchi, J. Takenawa, H. Nakayama, J. Kimura, and J. Fujita. 1995. Induction of CL100 protein tyrosine phosphatase following transient forebrain ischemia in the rat brain. J. Cereb. Blood Flow Metab. 15:33-41.

37. Clowes, A.W., M.A. Reidy, and M.M. Clowes. 1983. Mechanisms of stenosis after arterial injury. Lab. Invest. 49:208-215.

38. Marshall, C.J. 1995. Specificity of receptor tyrosine kinase signaling: transient versus sustained extracellular signal-regulated kinase activation. Cell. 80:179-185.

39. Sun, H., N.K. Tonks, and D. Bar-Sagi. 1994. Inhibition of Ras-induced DNA synthesis by expression of the phosphatase MKP-1. Science (Wash. DC). 266:285-288. 